\title{
Determination of specific gravity of municipal solid waste
}

\author{
Nazli Yesiller ${ }^{\mathrm{a}, *}$, James L. Hanson ${ }^{\mathrm{b}, 1}$, Jason T. Cox ${ }^{\mathrm{b}, 2}$, Danielle E. Noce ${ }^{\mathrm{b}, 3}$ \\ ${ }^{a}$ Global Waste Research Institute, California Polytechnic State University, San Luis Obispo, CA 93407, USA \\ ${ }^{\mathrm{b}}$ Civil and Environmental Engineering Department, California Polytechnic State University, San Luis Obispo, CA 93407, USA
}

\section{A R T I C L E I N F O}

Keywords:

Municipal solid waste

Specific gravity

Compaction

Moisture content

Waste constituent

Waste placement

Degradation

Decomposition

Particle density

\begin{abstract}
A B S T R A C T
This investigation was conducted to evaluate experimental determination of specific gravity $\left(G_{s}\right)$ of municipal solid waste (MSW). Water pycnometry, typically used for testing soils was adapted for testing MSW using a large flask with $2000 \mathrm{~mL}$ capacity and specimens with $100-350 \mathrm{~g}$ masses. Tests were conducted on manufactured waste samples prepared using US waste constituent components; fresh wastes obtained prior and subsequent to compaction at an MSW landfill; and wastes obtained from various depths at the same landfill. Factors that influence specific gravity were investigated including waste particle size, compaction, and combined decomposition and stress history. The measured average specific gravities were 1.377 and 1.530 for as-prepared/uncompacted and compacted manufactured wastes, respectively; 1.072 and 1.258 for uncompacted and compacted fresh wastes, respectively; and 2.201 for old wastes. The average organic content and degree of decomposition were $77.2 \%$ and $0 \%$, respectively for fresh wastes and $22.8 \%$ and $88.3 \%$, respectively for old wastes. The $G_{s}$ increased with decreasing particle size, compaction, and increasing waste age. For fresh wastes, reductions in particle size and compaction caused occluded intraparticle pores to be exposed and waste particles to be deformed resulting in increases in specific gravity. For old wastes, the high $G_{s}$ resulted from loss of biodegradable components that have low $G_{s}$ as well as potential access to previously occluded pores and deformation of particles due to both degradation processes and applied mechanical stresses. The $G_{s}$ was correlated to the degree of decomposition with a linear relationship. Unlike soils, the $G_{s}$ for MSW was not unique, but varied in a landfill environment due both to physical/mechanical processes and biochemical processes. Specific gravity testing is recommended to be conducted not only using representative waste composition, but also using representative compaction, stress, and degradation states.
\end{abstract}

\section{Introduction}

Specific gravity is broadly defined as the ratio of the density (mass of a unit volume) of a substance to the density of a standard reference substance. The definition used in geotechnical engineering is "the ratio of the mass of a unit volume of soil solids to the mass of the same volume of gas-free distilled water at $20^{\circ} \mathrm{C}$ " (ASTM D854), where the specific gravity is expressed as:

$G_{s}=\frac{\rho_{s}}{\rho_{w}}$

\footnotetext{
* Corresponding author. Tel.: +1 805756 2932; fax: +1 8057566330 . E-mail addresses: nyesille@calpoly.edu (N. Yesiller), jahanson@calpoly.edu (J.L. Hanson), jcox01@calpoly.edu (J.T. Cox), danielle.e.noce@gmail.com (D.E. Noce). 1 Tel.: +1 805756 6227; fax: 18057566330 .

2 Tel.: +1 559905 8410; fax: +1 8057566330 .

3 Tel: +1 760641 3947; fax: 18057566330 .
}

where $G_{s}$ is the specific gravity of soil solids, $\rho_{s}$ is the density of soil solids, and $\rho_{w}$ is the density of water at $20^{\circ} \mathrm{C}$. The same units are used for the densities resulting in the dimensionless parameter $G_{s}$.

Specific gravity is used in geotechnical and geoenvironmental engineering in calculation of basic phase (i.e., weight-volume) relations including void ratio, porosity, volumetric water content, degree of saturation, and unit weight of soil. The parameter $G_{s}$ can be applied to other geomaterials such as MSW. If $G_{s}$ is known, particle (i.e., dry solid) density can be calculated readily using Eq. (1). Geotechnical engineering provides a general framework for determination of engineering properties and behavior of municipal solid waste (MSW). Geotechnical engineering approaches commonly have been adapted to determine compaction, hydraulic conductivity, shear strength, and compressibility/settlement characteristics of MSW (e.g., Hudson et al., 2004; Qian et al., 2005; Hanson et al., 2010a). These approaches require estimation of basic weightvolume relations including specific gravity of waste solids for MSW analyses. In addition, specific gravity is a fundamental 
material property used in design calculations as well as modeling for predicting behavior of landfill systems (e.g., McDougall, 2007; Gourc et al., 2010; Bareither et al., 2012).

Specific gravity of soils typically is determined using water pycnometry (e.g., ASTM D854). Testing for waste specific gravity is complicated by several factors including: large particle sizes; heterogeneous mixture of particles (size, shape, and material composition); relative specific gravity of individual particles with respect to water; complex particle microstructure; and potential interaction with water. Particles with specific gravity less than water may float in the test setup. Waste constituents with occluded intraparticle voids may bias specific gravity measurements. These voids may be dry or partially or fully saturated. Compressible particles also may influence measurements. Furthermore, absorption or dissolution reactions with waste constituents may influence determination of specific gravity. Use of liquids other than water or gas pycnometry may resolve some of the testing issues. However, prescience of the wide variety and complex nature of constituent components of MSW is not possible for selecting a test fluid that could be used for all potential waste materials without any physical or chemical interactions.

Water pycnometry was adopted by Hettiarachchi (2005), Entenmann and Wendt (2007), Reddy et al. (2009a, 2011), Breitmeyer (2011), and Wu et al. (2012) to determine specific gravity of MSW (Table 1). The ASTM standard method for determination of $G_{s}$ of soils, D854, was used directly in some studies. This test method requires testing on solids smaller than $4.75 \mathrm{~mm}$ diameter (No. 4 sieve size) and a pycnometer with a minimum capacity of $250 \mathrm{~mL}$. Use of a $500-\mathrm{mL}$ pycnometer is common in geotechnical engineering practice with a recommended test specimen mass between 50 and $100 \mathrm{~g}$ for fine- to coarse-grained soils, respectively. Tests were conducted on 100-g specimens of a manufactured MSW sample with particle sizes less than $5 \mathrm{~mm}$ and the $G_{s}$ was determined to be 1.6 by Hettiarachchi (2005). $G_{s}$ was determined on shredded fresh (from active face) and old ( 1.5 years) wastes from an MSW landfill in the US. The measured specific gravities were 0.85 and 0.97 for fresh and old wastes, respectively (Reddy et al., 2009a). Tests were conducted on fresh and degraded manufactured wastes by Reddy et al. (2011). The $G_{s}$ was determined to be 1.09 for the fresh wastes, whereas the $G_{s}$ varied from 2.05 to 2.47 for specimens that underwent low to high degradation, respectively. Tests were conducted on waste samples obtained from shallow, middle, and deep layers of an MSW landfill in China by $\mathrm{Wu}$ et al. (2012). The particle size distributions of the waste samples from the three layers in the landfill indicated that 50$65 \%$ of the particle sizes were larger than $4.75 \mathrm{~mm}$. Details were not presented, but tests may have been conducted on only a fraction of the waste samples. The $G_{s}$ was reported to be $1.51,1.88$, and 2.14 for shallow, middle, and deep layers, respectively (Wu et al., 2012). Water pycnometry also was used to test mechanically and biologically pre-treated waste by Entenmann and Wendt (2007), who reported results in terms of density of solid particles with values between 1.58 and $1.98 \mathrm{~g} / \mathrm{cm}^{3}$.

A modified version of ASTM D854 was used by Breitmeyer (2011) on MSW specimens with particle sizes less than $25 \mathrm{~mm}$. Tests were conducted using a two-chambered vessel $(75-\mathrm{mm}$ diameter by $300-\mathrm{mm}$ height) separated by a perforated disk, which prevented floating of low specific gravity particles. The $G_{s}$ was determined to be 1.34 for shredded and recombined relatively fresh (3-4 month old) wastes obtained from an MSW landfill. The $G_{s}$ was determined to be $1.65,1.80$, and 1.90 for shredded and recombined relatively fresh wastes obtained from the same MSW landfill that had undergone low, medium, and high levels of degradation, respectively in laboratory reactors (Breitmeyer, 2011).

Limited data is available on factors that influence waste specific gravity. $G_{s}$ has only been related to degradation. $G_{s}$ was reported to increase with decreasing organic content for samples obtained from an MSW landfill in the US (Reddy et al., 2009a) and for manufactured wastes that were subjected to degradation in the laboratory (Reddy et al., 2011). The specific gravities were 0.85 and 0.97 and

Table 1

Summary of previous specific gravity investigations.

\begin{tabular}{|c|c|c|c|c|}
\hline Material & Test & Details & $G_{s}$ & References \\
\hline Manufactured waste & ASTM D854 & $\begin{array}{l}\text { US representative waste stream } \\
100 \mathrm{~g} \text { specimens } \\
\text { Particle sizes less than } 5 \mathrm{~mm}\end{array}$ & 1.6 & Hettiarachchi (2005) \\
\hline $\begin{array}{l}\text { Mechanically and biologically } \\
\text { pre-treated waste }\end{array}$ & $\begin{array}{l}\text { Water } \\
\text { Pycnometry }\end{array}$ & Waste samples obtained prior to disposal from a German landfill & $1.58-1.98^{\mathrm{a}}$ & $\begin{array}{l}\text { Entenmann and } \\
\text { Wendt (2007) }\end{array}$ \\
\hline Fresh shredded waste & ASTM D854 & $\begin{array}{l}\text { Samples obtained from active face of a landfill in US } \\
\text { Sample collection prior or post compaction not reported } \\
\text { Max. particle size was } 40 \mathrm{~mm}\end{array}$ & 0.85 & Reddy et al. (2009a) \\
\hline Old shredded waste & ASTM D854 & $\begin{array}{l}\text { Samples obtained from } 20 \mathrm{~m} \text { depth at a landfill in US } \\
\text { Waste age was } 1.5 \text { years } \\
\text { Max. particle size was } 40 \mathrm{~mm}\end{array}$ & 0.97 & Reddy et al. (2009a) \\
\hline Manufactured waste & ASTM D854 & $\begin{array}{l}\text { US representative waste stream } \\
\text { Max. particle size was } 40 \mathrm{~mm} \\
\text { Undegraded }\end{array}$ & 1.09 & Reddy et al. (2011) \\
\hline Manufactured waste & ASTM D854 & $\begin{array}{l}\text { US representative waste stream } \\
\text { Max. particle size was } 40 \mathrm{~mm} \\
\text { Degraded }\end{array}$ & $2.05-2.47$ & Reddy et al. (2011) \\
\hline Relatively fresh waste & $\begin{array}{l}\text { Modified } \\
\text { ASTM D854 }\end{array}$ & $\begin{array}{l}\text { Shredded and recombined relatively fresh ( } 3-4 \text { month old) wastes } \\
\text { obtained from a landfill in US } \\
\text { Max. particle size was } 25 \mathrm{~mm}\end{array}$ & 1.34 & Breitmeyer (2011) \\
\hline Laboratory degraded waste & $\begin{array}{l}\text { Modified } \\
\text { ASTM D854 }\end{array}$ & $\begin{array}{l}\text { Same waste as above after low }(\mathrm{L}) \text {, medium }(\mathrm{M}) \text {, and high }(\mathrm{H}) \\
\text { degradation in the laboratory } \\
\text { Max. particle size was } 25 \mathrm{~mm}\end{array}$ & $\begin{array}{l}1.65(\mathrm{~L}), 1.80(\mathrm{M}) \\
1.90(\mathrm{H})\end{array}$ & Breitmeyer (2011) \\
\hline Old waste & ASTM D854 & $\begin{array}{l}\text { Wastes obtained from shallow (S), middle (M), and deep (D) layers } \\
\text { from a landfill in China }\end{array}$ & $\begin{array}{l}1.51(\mathrm{~S}), 1.88(\mathrm{M}) \\
2.14(\mathrm{D})\end{array}$ & Wu et al. (2012) \\
\hline
\end{tabular}

a Converted to $G_{s}$. 
the organic contents (ASTM D2974) were 76\% and 63\% for fresh and 1.5 year old wastes, respectively (Reddy et al., 2009a). The specific gravity increased from 1.09 for fresh to 2.47 for highly degraded manufactured waste as the organic content (ASTM D2974) decreased from $57.5 \%$ to $15.5 \%$, respectively (Reddy et al., 2011). Bareither et al. (2012) provided a linear relationship between $G_{s}$ and reactor methane yield in laboratory degradation experiments conducted on waste samples obtained from an MSW landfill in the US. The $G_{s}$ increased from 1.65 to 1.80 to 1.90 as the methane yield increased from 5.3 (low degradation) to 14.3 (medium degradation) to 18.7 (high degradation) $\mathrm{L}-\mathrm{CH}_{4} / \mathrm{g}$-dry. The biochemical methane potential (BMP) also was determined in the investigation; however,

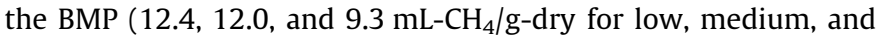
high degradation, respectively) was not correlated to $G_{s}$ as strongly as the methane yield.

Particle density for MSW constituent components or overall MSW also has been reported in the literature. In general, these data were obtained using indirect methods and not through direct measurements. Particle densities for select waste constituents were provided by Landva and Clark (1990) based on a combination of approaches: data obtained from literature, densities determined using mass/volume measurements, densities determined using assumed $G_{s}$ values, and entirely assumed values. The data were $1.0 \mathrm{Mg} / \mathrm{m}^{3}$ for food waste; $0.3 \mathrm{Mg} / \mathrm{m}^{3}$ for garden waste; $0.4 \mathrm{Mg}$ / $\mathrm{m}^{3}$ for paper; $1.1 \mathrm{Mg} / \mathrm{m}^{3}$ for plastic and rubber; $0.3 \mathrm{Mg} / \mathrm{m}^{3}$ for textiles; $0.45 \mathrm{Mg} / \mathrm{m}^{3}$ for wood; $6.0 \mathrm{Mg} / \mathrm{m}^{3}$ for metal; $2.9 \mathrm{Mg} / \mathrm{m}^{3}$ for glass and ceramics; and $1.8 \mathrm{Mg} / \mathrm{m}^{3}$ for ash, rock, and soil (Landva and Clark, 1990). Waste solid density was provided by Olivier and Gourc (2007) for a manufactured waste sample based on individual waste constituent densities. The density was calculated by averaging the density of solid constituents determined using the mass of the solids (including any bound water) and the volume of the solids for a given material. The reported waste solid density was $1.03 \mathrm{Mg} / \mathrm{m}^{3}$, which was indicated to be underestimated due to testing difficulties. Data were provided by Stoltz et al. (2010a) for specimens obtained from incoming wastes (mixture of household and non-hazardous industrial waste) at an MSW landfill in France. The solid density was calculated using measurements obtained from compression tests in a specially designed oedopermeameter operated in a manner similar to a gas pycnometer for determination of waste gas content. The average solid density of the waste specimens was $1.65 \mathrm{Mg} / \mathrm{m}^{3}$ in these tests. Stoltz et al. (2010a) also provided an estimate of solid density as $1.37 \mathrm{Mg} / \mathrm{m}^{3}$ based on a weighted average of individual constituent densities obtained from the literature. The discrepancy between the estimated and the experimental value was explained with uncertainties in obtaining representative composition of the tested wastes and potential approximations involved in the constituent component data provided in the literature.

Variations in particle density and specific gravity of wastes due to applied stress were reported in the literature. These investigations did not include direct measurement of particle density or specific gravity, but backcalculation of the parameters using data obtained in the test programs. Increase in average particle density was observed in large-scale in situ 1-D compression tests on untreated fresh waste (Powrie and Beaven, 1999). The particle density increased from 0.876 to $1.303 \mathrm{Mg} / \mathrm{m}^{3}$ with an increase in average stress from 34 to $463 \mathrm{kPa}$ and associated increase in waste dry density from 0.39 to $0.71 \mathrm{Mg} / \mathrm{m}^{3}$. Similar observations were made by Beaven (2000) for pulverized waste, where the particle density increased from 0.59 to $0.93 \mathrm{Mg} / \mathrm{m}^{3}$ with an increase in average stress from 35 to $486 \mathrm{kPa}$.

Hanson et al. (2010a) postulated that the unit weight and specific gravity of waste solids increased with applied pressure during compaction to explain sharp increases in the dry unit weight of wastes with relatively low change in moisture content between
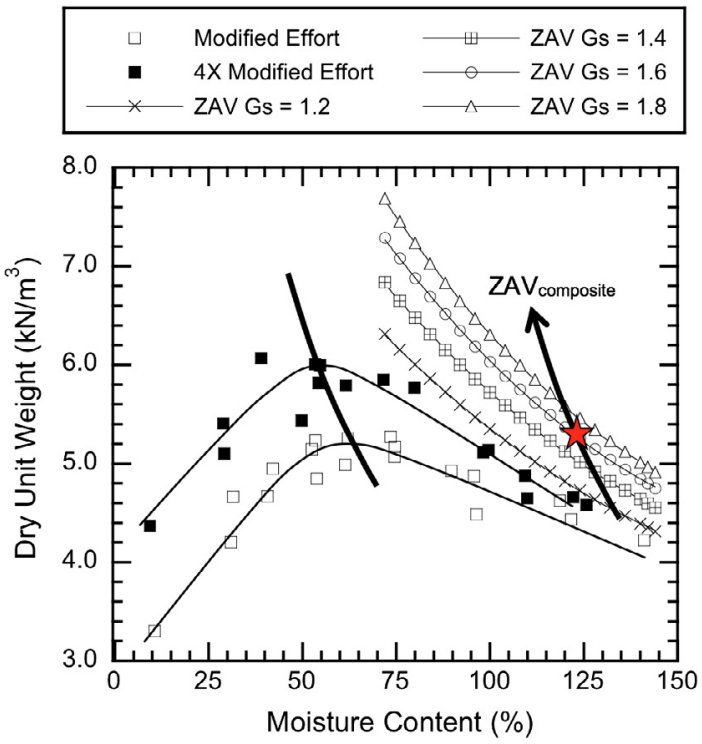

Fig. 1. Compaction plot with variable ZAV (modified from Hanson et al., 2010a).

different compactive efforts in laboratory and field compaction tests. Unlike soils, the zero air voids (ZAV) curve (i.e., 100\% saturation line) for wastes was not unique and was not associated with a single $G_{s}$ value. The ZAV curve provides a theoretical upper limit for paired dry unit weight/moisture content data points in the compaction domain. Hanson et al. (2010a) proposed a new composite zero air voids curve ( $Z_{\text {AV }}$ composite $)$ for MSW corresponding to progressively increasing $G_{s}$ (Fig. 1 ) to ensure similar alignment between the singular ZAV curve and the steep line of optimums. The $Z_{A V} V_{\text {composite }}$ was positioned parallel to the line of optimums established using equivalent degrees of saturation at the peak of the compaction curves associated with the different compactive efforts.

This investigation was conducted to provide a systematic and comprehensive evaluation of experimental determination of municipal solid waste specific gravity. The objectives of the investigation were twofold: to assess the applicability of the common soil testing procedure, namely water pycnometry, for testing municipal solid waste and to determine the factors that influence the specific gravity of wastes. Tests were conducted on manufactured wastes, fresh wastes from a landfill, and old wastes from a landfill. Recommendations are provided based on the results of the investigation.

\section{Experimental testing program}

Tests were conducted in the laboratory to determine specific gravity of municipal solid waste. A total of three categories of tests were conducted to determine the range of $G_{s}$ for MSW and the factors that affect $G_{s}$. Category I tests were conducted on manufactured wastes to investigate the factors that affect specific gravity without the influence of compositional variability between test specimens. In particular, the effects of component particle size and compaction conditions on specific gravity were assessed. Category II tests were conducted on MSW samples obtained from Santa Maria Regional Landfill located in Santa Maria, California, USA. The samples were collected from the active face at the landfill immediately before and after compaction. The effects of compaction on fresh MSW on a field scale were assessed in Category II tests. Finally, Category III tests included testing of old wastes (waste ages between 0.7 and 6 years) obtained at depth from the same landfill to determine the evolution of MSW $G_{s}$ over time 
under the combined effects of biochemical degradation and mechanical stress from overlying layers.

\subsection{Materials}

The manufactured waste samples used in Category I tests were prepared using MSW constituent compositions provided by USEPA (2010): $16 \%$ paper and paperboard, $21 \%$ food, $17 \%$ plastics, $8 \%$ yard waste, $8 \%$ wood, $9 \%$ metals, $5 \%$ glass, $7 \%$ textiles, $4 \%$ rubber and leather, $3 \%$ inorganic waste, and $2 \%$ other wastes. The composition was similar to the waste samples used by Wong (2009) and Hanson et al. (2010a) in determination of geotechnical engineering properties of MSW including compaction characteristics, shear strength, hydraulic conductivity, and compressibility. Detailed compositional characteristics of the specimens are provided in $\mathrm{Ta}-$ ble 2 . The moisture content of the manufactured waste was measured to be $2.2 \%$. All moisture contents reported herein are gravimetric dry weight based. The $G_{s}$ for the manufactured waste was calculated with Eq. (2) to be 1.366 using a weighted average of the individual specific gravity values presented in Table 2 for the waste constituents.

$G_{s}=\frac{\left(\sum_{i=1}^{n} M_{s i}\right)}{\left[\sum_{i=1}^{n} \frac{M_{s i}}{G_{s i} \cdot \rho_{w}}\right] \cdot \rho_{w}}$

where $M_{s i}$ is the mass of an individual waste constituent, $G_{s i}$ is the specific gravity of an individual waste constituent, and $\rho_{w}$ is the density of water at $20^{\circ} \mathrm{C}$.

Manufactured waste tests were conducted on three size fractions, referred to as coarse, medium, and fine to evaluate the influence of particle size on determination of specific gravity. An equivalent particle diameter was calculated for the manufactured wastes in each size fraction as the composite material was not suitable for conventional sieve analysis (particles have been retained unrepresentatively on large sieve sizes due to particle shapes for "long and thin" components as well as due to electrostatic forces for lightweight materials such as plastic components). Several particles were measured for each waste constituent and size fraction. For non-spherical components (e.g., paper, food, plastics, textile, rubber, and leather), an apparent volume was calculated using the measured length, width, and thickness of a particle. Then, an equivalent diameter for the particle was backcalculated from this volume. For relatively rounded particles such as fine wood, fine aluminum, and fine glass, particle diameter was directly measured using a pair of calipers. The equivalent particle diameters for each size fraction were determined using a weighted average of the constituent components. The resulting diameters were $14.2,8.5$, and $4.4 \mathrm{~mm}$ for coarse, medium, and fine fractions, respectively. Size characteristics of the waste constituents also are provided in Table 2. A photographic depiction of the constituent components of the manufactured MSW samples prepared to the three size fractions is presented in Fig. 2.

The fresh waste samples for Category II tests were obtained from Santa Maria Regional Landfill located in California, USA. The waste composition at the site included by weight approximately $38 \%$ residential waste, $39 \%$ commercial waste, and $23 \%$ self-delivered waste consisting of miscellaneous items. The samples were collected from the active face of the landfill. First, samples were collected from as-delivered wastes at the active face prior to compaction. Next, samples were collected immediately after compaction of the wastes at the active face. Test specimens were obtained from waste samples with masses of $10 \mathrm{~kg}$ collected from the landfill for uncompacted conditions and also compacted conditions. The specimens were used for determination of physical properties including moisture content and specific gravity. Each sample was mixed thoroughly in a large container prior to obtaining a single representative test specimen from that sample. Moisture contents of the as-delivered (uncompacted) and compacted fresh waste samples were determined to be $33.4 \%$ and $37.1 \%$, respectively. Evidence of shredding of plastic bags, clothes, cardboard, and paper as well as crushing and distortion/compression of wood, glass bottles, plastic bottles and containers, and aluminum cans and other metal containers were visible for compacted fresh wastes in comparison to the uncompacted fresh wastes. Photographs of the fresh wastes are presented in Fig. 3.

The old waste samples for Category III tests were obtained from the same MSW landfill. Samples were obtained from boreholes drilled using a hollow stem auger at four locations at the landfill (designated as $\mathrm{BH} 1, \mathrm{BH} 2, \mathrm{BH} 5$, and $\mathrm{BH} 6$ ). Some tearing of plastic bags and other components was observed at shallow depths during drilling. Samples were collected from depths ranging between 1.5 and $14.6 \mathrm{~m}$ with corresponding waste ages between 0.7 and 6 years, respectively. Waste samples with masses up to $1.5 \mathrm{~kg}$ were obtained at each measurement depth for determination of physical properties including specific gravity, moisture content, particle size distribution, and organic content. The old wastes generally had a soil-like appearance. Inert and partially degraded waste constituents such as rocks, metal, plastics, wood, and paper were observed

Table 2

Properties of manufactured waste specimens.

\begin{tabular}{|c|c|c|c|c|c|c|}
\hline \multirow[t]{2}{*}{ Waste constituent } & \multirow[t]{2}{*}{ Description } & \multirow[t]{2}{*}{ Fraction (\%) } & \multirow[t]{2}{*}{$G_{s}^{\mathrm{a}}$} & \multicolumn{3}{|l|}{ Particle size (mm) } \\
\hline & & & & Coarse & Medium & Fine \\
\hline Paper & Printer paper coupons & 13 & 1.53 & $50.8 \times 50.8$ & $25.4 \times 25.4$ & $12.7 \times 12.7$ \\
\hline Cardboard & Cardboard coupons & 3 & 1.53 & $50.8 \times 50.8$ & $25.4 \times 25.4$ & $12.7 \times 12.7$ \\
\hline Food & Chopped and crushed dog food biscuts & 21 & 1.22 & $38.1 \times 25.4$ & $12.7 \times 12.7$ & Passes no. 4 sieve \\
\hline HDPE & Milk carton coupons and HDPE chips & 13 & 0.95 & $25.4 \times 25.4$ & $12.7 \times 12.7$ & Passes no. 4 sieve \\
\hline LDPE & Trash bag coupons & 4 & 0.92 & $50.8 \times 50.8$ & $25.4 \times 25.4$ & $6.35 \times 6.35$ \\
\hline Yard trimmings & Chopped leaves and shredded grass & 8 & 0.94 & $50.8 \times 25.4$ leaves & $19.05 \times 19.05$ leaves & Passes no. 4 sieve \\
\hline Wood & Wood blocks and wood shavings & 8 & 1.53 & $25.4 \times 19.05 \times 12.7$ & $12.7 \times 12.7 \times 6.35$ & Passes no. 8 sieve \\
\hline Steel & Chopped nails & 6.5 & 7.86 & 38.1 length & 19.05 length & 6.35 length \\
\hline Aluminum & Aluminum can coupons and shavings & 2 & 2.7 & $25.4 \times 25.4$ & $12.7 \times 12.7$ & Passes no. 4 sieve \\
\hline Other metals & Scrap metal coupons & 0.5 & 2.7 & $19.05 \times 19.05$ & $12.7 \times 12.7$ & $6.35 \times 6.35$ \\
\hline Glass & Crushed glass bottles & 5 & 2.6 & $12.7 \times 12.7$ & $6.35 \times 6.35$ & Passes no. 4 sieve \\
\hline Textile & Textile coupons & 7 & 1.27 & $50.8 \times 50.8$ & $25.4 \times 25.4$ & $12.7 \times 12.7$ \\
\hline Rubber & Shoe rubber coupons and shredded tire & 3.4 & 1.1 & $19.05 \times 19.05 \times 3.18$ & $6.35 \times 6.35$ & Passes no. 4 sieve \\
\hline Leather & Shoe leather coupons & 0.7 & 0.86 & $19.05 \times 19.05$ & $12.7 \times 12.7$ & $3.175 \times 3.175$ \\
\hline Inorganic waste & Soils & 3 & 2.65 & 12.7 diameter & Retained on no. 8 sieve & Passes no. 200 sieve \\
\hline Other & Crushed concrete fragments & 2 & 2.6 & $19.05 \times 19.05$ & $12.7 \times 6.35$ & Passes no. 4 sieve \\
\hline
\end{tabular}

a Obtained from Wong (2009). 


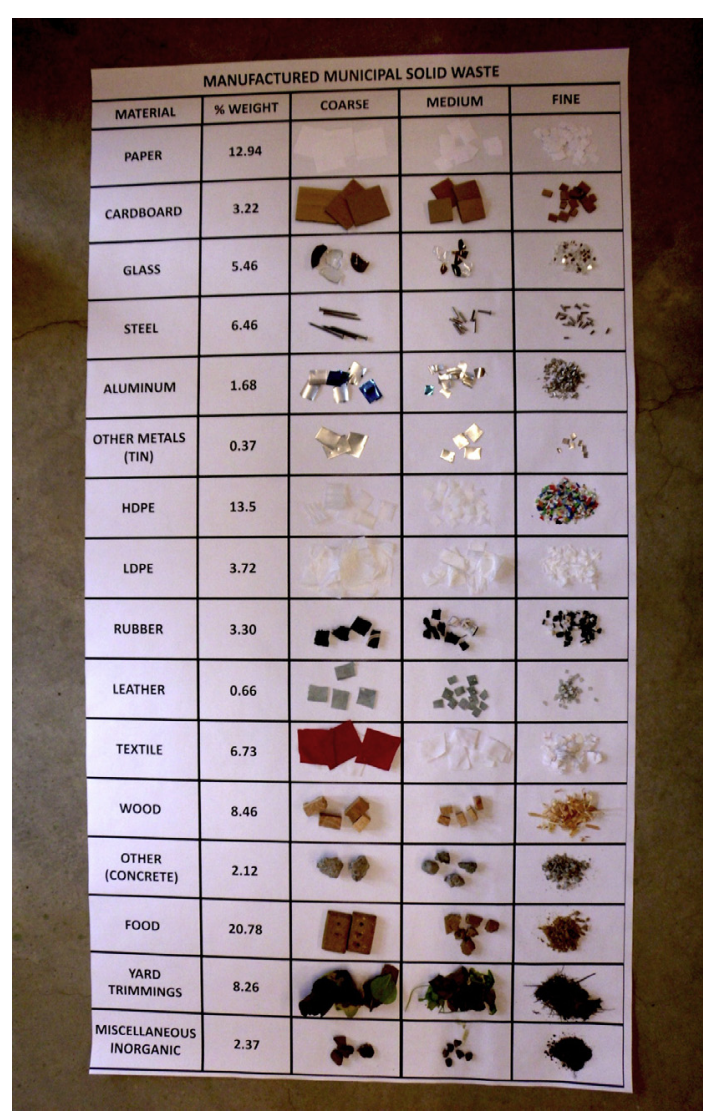

Fig. 2. Photograph of waste constituents prepared to three particle size fractions.

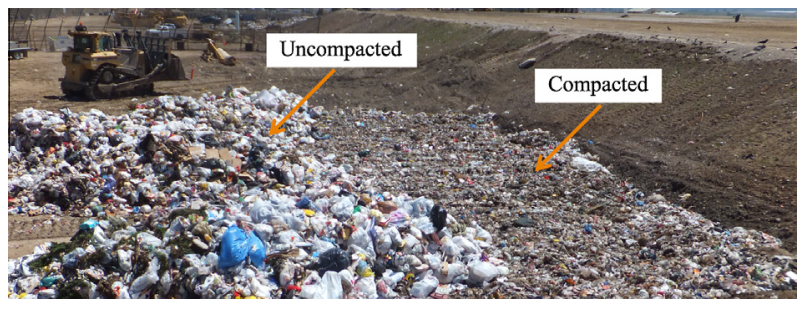

Fig. 3. Fresh wastes sampled at the landfill site.

in the old waste samples. Photographs of the old waste samples are presented in Fig. 4. The moisture contents of the wastes were determined to be between $5.4 \%$ and $48.6 \%$. The moisture contents generally were lower at shallow depths and higher at great depths. Particle size distribution of the old wastes was determined using sieve analysis of the samples obtained from $\mathrm{BH} 2$ at 6.4 and $13.7 \mathrm{~m}$ depths (Fig. 5). The particle size varied between 0.075 and $9.5 \mathrm{~mm}$ with a generally well-graded distribution. Significant differences were not present between the tested specimens from the two depths. The coefficient of uniformity was approximately 13.4 and the coefficient of curvature was approximately 0.6 .

\subsection{Methodology}

Laboratory specific gravity tests were conducted using water pycnometry generally following the procedures used for soil testing (ASTM D854). Water pycnometry was selected as welldefined test procedures and significant experience is present with the use of this method. In addition, the method is relatively

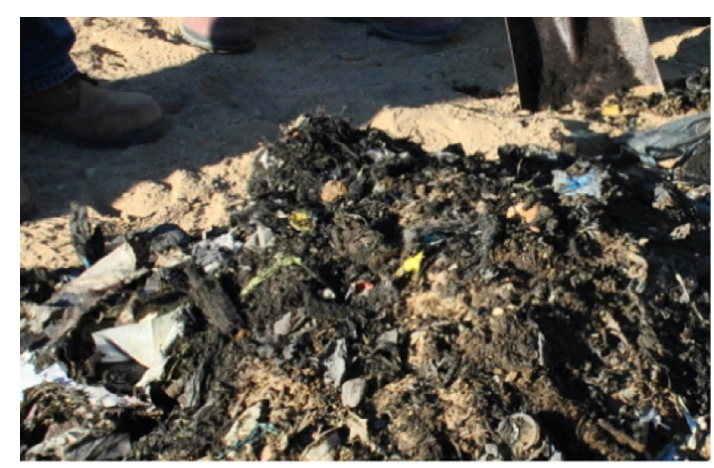

(a) Old waste from shallow depth

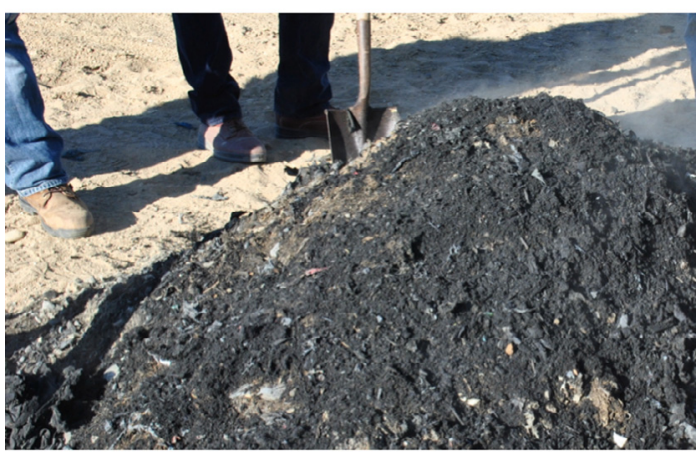

(b) Old waste from great depth

Fig. 4. Old wastes sampled at the landfill site.

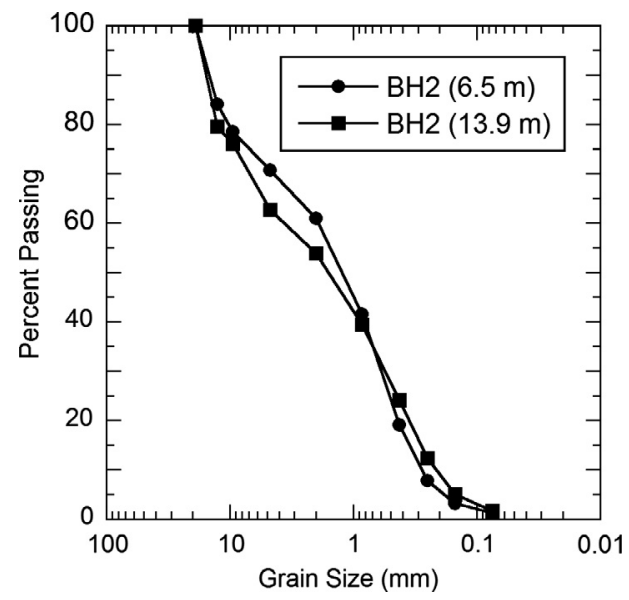

Fig. 5. Particle size distribution of old wastes.

straightforward in comparison to gas pycnometry or testing with liquids other than water.

The standard soil testing procedure was adapted for testing MSW. The tests were conducted using an Erlenmeyer flask with a volume of $2000 \mathrm{~mL}$ to accommodate the relatively large particle sizes of MSW in comparison to typical soils (Fig. 6). The maximum particle size used in the tests was approximately $50-65 \mathrm{~mm}$. The particle sizes of the old wastes generally were smaller than the particle sizes of the manufactured and fresh wastes. The waste masses used in the test program varied between nominally 100 and $350 \mathrm{~g}$. In general, lower masses were used for the relatively bulky (due to low $G_{s}$ components such as paper and plastics) manufactured and fresh wastes, whereas higher masses were used for the soil-like, smaller particle size old wastes in the tests. Special care was taken to prevent potential floating of relatively low 


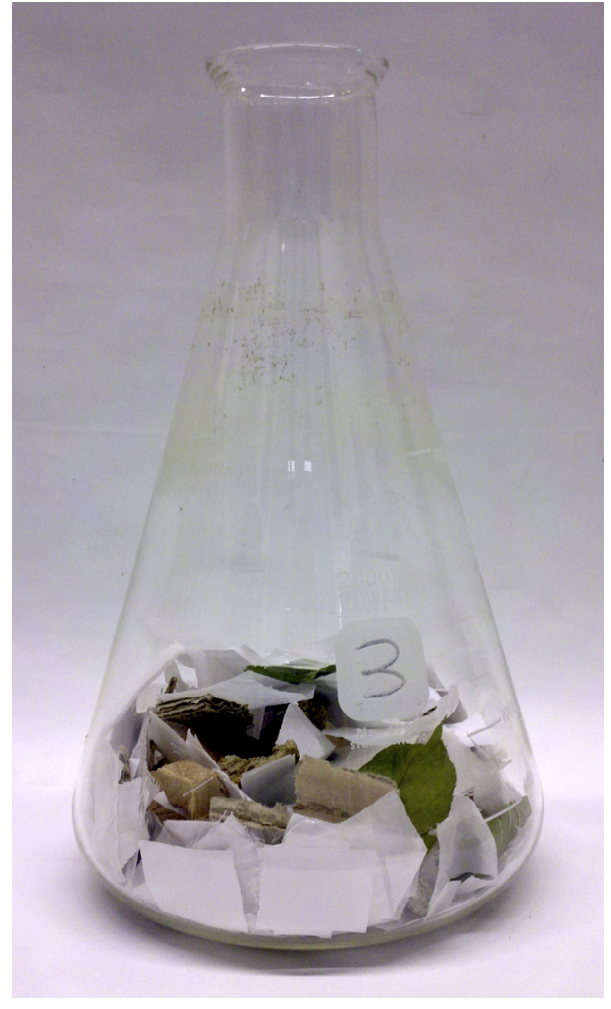

Fig. 6. Erlenmeyer flask with dry waste specimen.

specific gravity waste components such as certain types of plastics. The amount of such components was minimized in the uppermost layer of wastes placed in the flask for testing by physically arranging the given test specimen. The narrowing neck section of the Erlenmeyer flask also was effective in keeping the waste constituents in place due to mechanical bridging thus preventing propensity to float above the fluid surface.

For Category I tests, analyses were conducted directly on asprepared manufactured waste samples and on compacted manufactured waste samples. Duplicate specimens were tested for the as-prepared (i.e., uncompacted) condition to assess the repeatability of the specific gravity tests. The compaction conditions were selected using the data provided in Hanson et al. (2010a). The wastes were compacted using four times $(4 \times)$ modified compaction effort used for compacting soils (ASTM D1557) as this level of energy application had been demonstrated to provide good representation of field waste compaction conditions based on comparison of laboratory and field MSW compaction tests (details presented in Hanson et al., 2010a). The number of blows was adjusted to provide four times the compaction energy as modified compaction effort for the small (i.e., $100 \mathrm{~g}$ ) test specimens.

The maximum dry unit weight $\left(\gamma_{\text {dmax }}\right)$ and optimum moisture content $\left(w_{\text {opt }}\right)$ were determined to be $6.0 \mathrm{kN} / \mathrm{m}^{3}$ and $56 \%$, respectively for the manufactured waste (Hanson et al., 2010a). Waste specimens were prepared by compaction at 30\% moisture content (dry side of optimum) and at $90 \%$ moisture content (wet side of optimum) with a resulting dry unit weight of approximately $5.3 \mathrm{kN} / \mathrm{m}^{3}$ for both moisture conditions. Specific gravity was determined on all waste particle size fractions for as-prepared and compacted specimens. In Category II fresh waste tests, specific gravity was determined directly on the waste samples collected from the field site. Normal compaction practices were used at the landfill site at the sampling locations. The old wastes also were tested at the as-sampled conditions.
The specific gravity testing procedure used in the experimental program consisted of the steps listed below:

- preparing pre-weighed waste specimen,

- if applicable, adding moisture and compacting pre-weighed waste specimen,

- calibrating the Erlenmeyer flask for mass and volume,

- placing the pre-weighed waste specimen in the Erlenmeyer flask,

- deairing deionized water,

- filling the flask $2 / 3$ full with the deaired, deionized water,

- placing waste and water filled flask on a shake table and connecting to a vacuum pump for approximately $1 \mathrm{~h}$ to deair the water-waste mixture in the flask,

- filling the remaining $1 / 3$ of Erlenmeyer flask with deaired, deionized water,

- placing the full flask into a temperature controlled container and allowing the flask to reach equilibrium (approximately $8 \mathrm{~h}$ ),

- recording the temperature and mass of the Erlenmeyer flask, and

- determining the specific gravity in accordance with the formulation provided in ASTM D854.

\section{Results and discussion}

\subsection{Results of specific gravity tests}

Results of all of the waste specific gravity tests are provided in Table 3. For Category I manufactured waste tests, the measured specific gravity overall varied from 1.339 to 1.570 , representing a specific gravity variation of 0.231 . The average specific gravity values were $1.377,1.523$, and 1.538 for as-prepared (i.e., uncompacted waste specimens), compacted at the dry of optimum moisture content, and compacted at the wet of optimum moisture content specimens, respectively. The experimentally determined $G_{s}$, (1.377) for the uncompacted manufactured waste specimens was similar to the calculated $G_{s}(1.366)$ using the weighted average of the individual specific gravities of the waste constituents (Section 2.1), indicating that the water pycnometry analysis was effective for the determination of the specific gravity.

For a given test condition (i.e., Tests $1-4$ ), the specific gravity of the manufactured wastes increased with decreasing waste particle size (Table 3 and Fig. 7). Increases in $G_{s}$ of wastes were between 0.055 and 0.103 as the specimen size decreased from coarse to fine. The increases were higher for the uncompacted specimens $(0.080$ and 0.103 ) than the compacted specimens ( 0.055 and 0.070$)$. The increases in $G_{s}$ with decreasing particle size were attributed to potential exposure of occluded intraparticle voids that were originally closed to the outside. Waste constituents that likely contained inaccessible pores included organic particles such as food, wood, and yard waste as well as rubber, leather, and cardboard components. The presence of the occluded voids was observed visually with naked eye for the food waste constituent (i.e., the dog biscuits) used in the test program. Systematic analysis of particle size effects on $G_{s}$ of MSW was not presented in the literature. However, data were provided for other materials such as volcanic rocks (Wesley, 2001; Tamari et al., 2005) and an industrial byproduct (Millspaugh et al., 2010). The $G_{s}$ of volcanic scoria increased from 1.20 to 2.34 when the particle size decreased from $15 \mathrm{~mm}$ to $<74 \mu \mathrm{m}$ (Wesley, 2001) and from 2.55 to 2.79 when the particle size decreased from $4.75 \mathrm{~mm}$ to $35 \mu \mathrm{m}$ (Tamari et al., 2005). For chromium ore processing residue, the $G_{s}$ increased from 3.146 to 3.355 and 2.711 to 2.720 for two types of ore residue when the ore was ground to a nominal particle size of $80 \mu \mathrm{m}$ (unground particle sizes were not provided) (Millspaugh et al., 2010). Presence of closed intraparticle voids and exposure of these voids 
Table 3

Specific gravity test results.

\begin{tabular}{|c|c|c|c|c|c|}
\hline Test $^{\mathrm{a}}$ & Description & Test details & Specimen mass $(\mathrm{g})$ & $G_{s}\left(20^{\circ} \mathrm{C}\right)$ & $G_{s}$ Average $^{\mathrm{b}}$ \\
\hline \multirow[t]{3}{*}{$M$} & As-prepared (uncompacted) & Coarse & 103.6 & 1.339 & 1.378 \\
\hline & & Medium & 100.54 & 1.376 & \\
\hline & & Fine & 99.53 & 1.419 & \\
\hline \multirow[t]{3}{*}{ M } & As-prepared (uncompacted) & Coarse & 100.06 & 1.326 & 1.376 \\
\hline & & Medium & 100.3 & 1.372 & \\
\hline & & Fine & 100.08 & 1.429 & \\
\hline \multirow[t]{3}{*}{ M } & Compacted - dry of optimum moisture content & Coarse & 100.07 & 1.497 & 1.523 \\
\hline & & Medium & 100.11 & 1.521 & \\
\hline & & Fine & 100.02 & 1.552 & \\
\hline \multirow[t]{3}{*}{ M } & Compacted - wet of optimum moisture content & Coarse & 100.07 & 1.500 & 1.538 \\
\hline & & Medium & 100.11 & 1.542 & \\
\hline & & Fine & 100.03 & 1.570 & \\
\hline $\mathrm{F}$ & Uncompacted & Active Face & 335.08 & 0.803 & 1.072 \\
\hline $\mathrm{F}$ & Uncompacted & Active Face & 324.92 & 1.248 & \\
\hline $\mathrm{F}$ & Uncompacted & Active Face & 186.69 & 1.388 & \\
\hline $\mathrm{F}$ & Uncompacted & Active Face & 184.04 & 1.178 & \\
\hline $\mathrm{F}$ & Uncompacted & Active Face & 261.03 & 0.741 & \\
\hline $\mathrm{F}$ & Compacted & Active Face & 186.09 & 1.254 & 1.258 \\
\hline $\mathrm{F}$ & Compacted & Active Face & 135.76 & 1.178 & \\
\hline $\mathrm{F}$ & Compacted & Active Face & 205.18 & 1.343 & \\
\hline $\mathrm{F}$ & Compacted & Active Face & 173.13 & 1.147 & \\
\hline $\mathrm{F}$ & Compacted & Active Face & 253.20 & 1.370 & \\
\hline 0 & BH1 & $1.9 \mathrm{~m}$ depth & 224.64 & 2.487 & 2.200 \\
\hline $\mathrm{O}$ & BH1 & $6.2 \mathrm{~m}$ depth & 144.26 & 1.962 & \\
\hline $\mathrm{O}$ & BH1 & $14.2 \mathrm{~m}$ depth & 149.97 & 2.151 & \\
\hline 0 & $\mathrm{BH} 2$ & $1.9 \mathrm{~m}$ depth & 311.4 & 2.113 & 2.166 \\
\hline $\mathrm{O}$ & $\mathrm{BH} 2$ & $6.5 \mathrm{~m}$ depth & 243.54 & 2.274 & \\
\hline $\mathrm{O}$ & $\mathrm{BH} 2$ & $13.9 \mathrm{~m}$ depth & 264.04 & 2.110 & \\
\hline 0 & BH5 & $2.5 \mathrm{~m}$ depth & 309.64 & 2.175 & 2.162 \\
\hline $\mathrm{O}$ & BH5 & $3.7 \mathrm{~m}$ depth & 281.52 & 2.288 & \\
\hline $\mathrm{O}$ & BH5 & $5.3 \mathrm{~m}$ depth & 335.6 & 2.251 & \\
\hline $\mathrm{O}$ & BH5 & $7.7 \mathrm{~m}$ depth & 316.35 & 2.166 & \\
\hline 0 & BH5 & $12.1 \mathrm{~m}$ depth & 290.88 & 2.041 & \\
\hline 0 & BH5 & $13.3 \mathrm{~m}$ depth & 342.57 & 2.051 & \\
\hline $\mathrm{O}$ & BH6 & $1.5 \mathrm{~m}$ depth & 283.64 & 2.247 & 2.276 \\
\hline $\mathrm{O}$ & BH6 & $3.7 \mathrm{~m}$ depth & 298.72 & 2.323 & \\
\hline 0 & BH6 & $7.1 \mathrm{~m}$ depth & 304.78 & 2.313 & \\
\hline 0 & BH6 & $9.9 \mathrm{~m}$ depth & 303.12 & 2.249 & \\
\hline $\mathrm{O}$ & BH6 & $12.1 \mathrm{~m}$ depth & 305.41 & 2.208 & \\
\hline 0 & BH6 & $14.6 \mathrm{~m}$ depth & 271.44 & 2.316 & \\
\hline
\end{tabular}

a M-manufactured, F-fresh, O-old.

b The measured $G_{s}$ values can be used to calculate particle density for the wastes using Eq. (1).

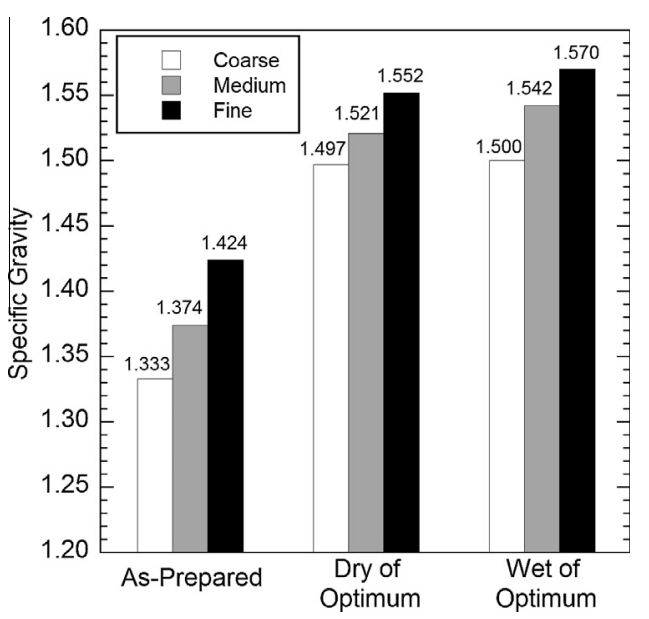

Fig. 7. Comparison of manufactured waste $G_{s}$ for three size fractions.

due to particle size reduction were indicated to be the mechanism for increased $G_{s}$. Visual SEM evidence of intraparticle voids and secondary porosity was provided for the chromium ore by Tinjum et al. (2008).
Waste specific gravity also increased due to compaction in Category I tests and Category II tests (Table 3 and Fig. 7). For manufactured wastes, the $G_{s}$ increased by 0.146 and 0.161 for dry of optimum moisture content and wet of optimum moisture content specimens, respectively compared to the as-prepared uncompacted specimens (Table 3 ). For fresh wastes, the $G_{s}$ increased by 0.186 from 1.072 for as-delivered uncompacted specimens to 1.258 for field-compacted specimens.

Crushing, breaking, and tearing of waste constituents due to compaction were observed for both manufactured and fresh wastes. A general decrease in particle size of the fresh wastes was observed visually (Fig. 3). The changes in particle size of the coarse manufactured waste samples were quantified using a sieving analysis (Table 4). The distribution of the particle sizes changed as the quantity of fine particles in the manufactured wastes increased due to compaction (Table 4).

For manufactured wastes, the particle sizes of the specimens compacted at the dry and wet of optimum moisture content were generally similar (Table 4) and in line with this trend, the specific gravity values of the compacted specimens were similar (1.523 and 1.538 for dry and wet of optimum moisture content, respectively) independent of the compaction moisture content in Category I tests. The average $G_{s}$ for the compacted wastes was 1.530 in these tests. Based on the manufactured waste tests, particle size had 
Table 4

Particle size variations due to compaction for manufactured wastes.

\begin{tabular}{|c|c|c|c|}
\hline Material & Passing $12.7 \mathrm{~mm}$ sieve (\%) & Passing 9.525 mm sieve (\%) & Retained on the pan (\%) \\
\hline Pre-compaction & 16 & 9 & 9 \\
\hline Post-compaction (dry of optimum moisture content) & 38 & 38 & 38 \\
\hline Post-compaction (wet of optimum moisture content) & 38 & 34 & 34 \\
\hline
\end{tabular}

more significant influence on the specific gravity of wastes than the compaction moisture content.

For manufactured wastes, the $G_{s}$ data for the as-prepared specimens and the compacted specimens were individually averaged and are presented as a function of equivalent particle diameter. The variation of $G_{s}$ with the particle sizes was linear in this test program for the range of equivalent particle diameters included in the analysis (Fig. 8). The relationships for the two cases (uncompacted and compacted) as presented in the figure were:

$G_{s}=1.4591-0.0091205^{*} D_{e q}($ uncompacted $)$

$G_{s}=1.5872-0.0063187^{*} D_{e q}($ compacted $)$

where $G_{s}$ is the specific gravity of waste solids and $D_{e q}$ is the equivalent diameter of the waste solids. Such relationships can be developed for use in experimental analysis of MSW when tests such as compaction, compression, etc. that may alter the physical condition of the MSW constituents are conducted.

The increase in $G_{s}$ due to compaction in Category I and II tests likely was affected by a similar mechanism to the increase observed due to changes in particle sizes. Compaction resulted in decreases in the particle sizes of the waste constituents and this decrease in turn provided access to occluded intraparticle voids that were originally closed to the outside. The reduced amount of occluded pores contributed to increases in the specific gravity of the wastes. Visual inspection of food, wood, and cardboard components indicated the presence of exposed voids in the compacted specimens. Such voids were not readily observed under uncompacted conditions. Crushing and compression of particles during compaction also may have contributed to the variations in $G_{s}$. Compression of waste particles and reduction in intraparticle voids due to expulsion of liquids and/or gases from these voids were proposed by Hudson et al. (2004) in large-scale experimental analysis and modeling of MSW compressibility. Based on manufactured waste tests, the increase in average $G_{s}$ due to compaction (0.1460.161 ) was higher than the increase in $G_{s}$ due to particle size reduc-

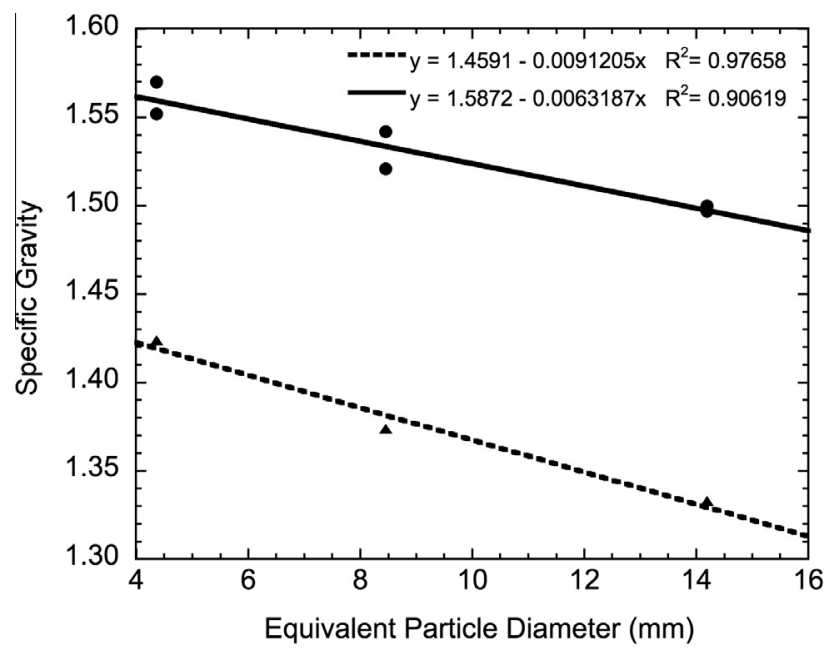

Fig. 8. Variation of manufactured waste $G_{s}$ with particle diameter for uncompacted and compacted specimens. tion alone (0.055-0.103) indicating potential compression of particles during compaction. Significant reduction in the volume of fresh wastes due to compaction was observed in the field (Fig. 3). Some of this volume reduction may have resulted from compression of particle constituents and intraparticle voids (similar to manufactured wastes) as opposed to compression of only interparticle voids. Overall, access to previously occluded intraparticle voids and compression of such voids both contributed to the increases in $G_{s}$ of compacted wastes.

The results of Category I tests were used to ascertain the location of the $Z A V_{\text {composite }}$ curve in Fig. 1. The $Z A V_{\text {composite }}$ presented on the original figure provided in Hanson et al. (2010a) was positioned approximately as $G_{s}$ testing was not conducted and $G_{s}$ data were not available. The authors had provided conceptual discussion of the $Z A V_{\text {composite }}$ curve. The precise location of the $Z A V_{\text {compos- }}$ ite was established using data from the specific gravity tests. The measured $G_{s}$ (1.538) was used with the waste dry unit weight of $5.3 \mathrm{kN} / \mathrm{m}^{3}$ and moisture content of $90 \%$ to determine the corresponding degree of saturation $(S)$ as $75.0 \%$ for the wet of optimum moisture content test. Using the degree of saturation along the line of optimums (55.5\%, provided in Hanson et al., 2010a) and the calculated degree of saturation (75\%) for the dry unit weight/moisture content pair of $5.3 \mathrm{kN} / \mathrm{m}^{3} / 90 \%$, the location of the $100 \%$ degree of saturation was scaled (point marked with star in Fig. 1). The $\mathrm{ZAV}_{\text {composite }}$ curve was then drawn parallel to the line of optimums on Fig. 1 passing through the newly marked point. The $G_{s}$ was backcalculated at this point to be 1.640 using the dry unit weight of $5.3 \mathrm{kN} / \mathrm{m}^{3}$, the degree of saturation of $100 \%$, and the water content of $124 \%$ (obtained from the figure). The backcalculated $G_{s}$ agreed with the variable $G_{s}$ trends presented on the figure (i.e., the backcalculated $G_{s}$ of 1.640 fell between the ZAV curves for $G_{s}$ of 1.6 and 1.8 , close to 1.64 graphically).

The $G_{s}$ for the old wastes in Category III tests varied between 2.162 and 2.276 with an average value of 2.201 based on the measurements conducted on the specimens obtained from the four boreholes (Table 3 ). The specific gravity values for old wastes were significantly higher than the data obtained for the manufactured and fresh wastes (Table 3). For waste depth as shallow as $1.5 \mathrm{~m}$ and waste age as low as 0.7 years, the $G_{s}$ had increased significantly above the values for both the incoming fresh wastes and the fresh wastes immediately after compaction. The average organic content of the fresh and old wastes was determined by igniting oven dry samples of waste at $450{ }^{\circ} \mathrm{C}$ and weighing residual ash content (ASTM D2974). The average organic content of the old wastes (22.8\%) was significantly lower than the average organic content of the fresh wastes (77.2\%). In addition to organic content, the degree of decomposition $(D O D)$ was calculated using the formulation provided by Andersland et al. (1981). The DOD, calculated using Eq. (5), provides an indication of the BMP of wastes (Reddy et al., 2011).

$D O D=\left(1-\frac{X_{f i}}{X_{f o}}\right) \frac{1}{\left(1-X_{f i}\right)}$

where $X_{f_{o}}$ is the initial organic fraction (average of fresh waste at the landfill) and $X_{f i}$ is the organic fraction after partial decomposition (for a given specimen of old waste). The degree of decomposition for fresh wastes was established as zero and the average degree 
A Current Study $\quad-\quad y=1.1658+0.011539 x R^{2}=0.998$

$\square \quad$ Reddy et al. (2011) $--y=1.182+0.016477 x R^{2}=0.942$

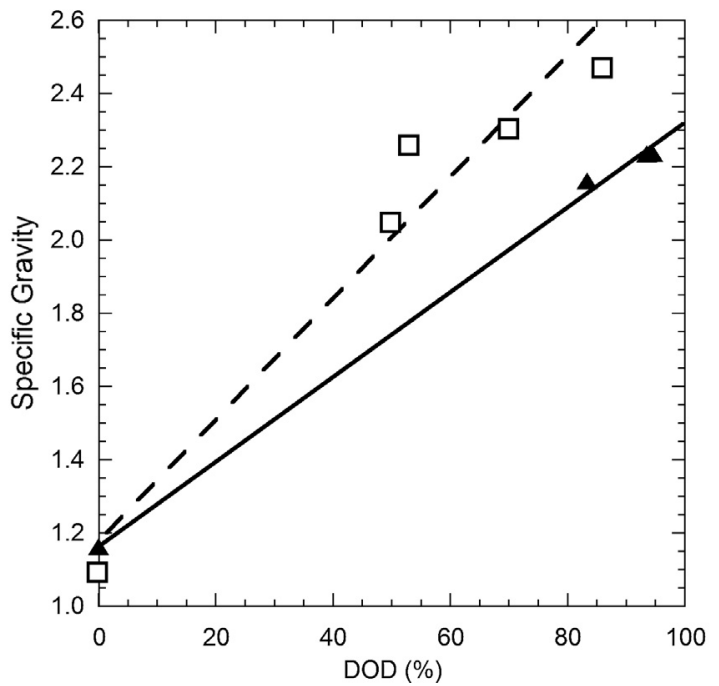

Fig. 9. Variation of $G_{s}$ with degree of decomposition.

of decomposition of the old wastes was calculated as $88.3 \%$. Variation of $G_{s}$ with degree of decomposition is presented in Fig. 9. Specific gravity varied linearly with degree of decomposition. A similar trend was observed between specific gravity and $D O D$ for manufactured wastes that were degraded in the laboratory when $G_{s}$ and DOD data obtained by Reddy et al. (2011) were included in Fig. 9. Average data for $G_{s}$, organic content, degree of decomposition, and waste temperature with depth are provided in Table 5. The highest $G_{s}$ values were consistent with the highest degrees of decomposition and occurred at mid-depths of the waste mass. Maximum temperatures at central locations in waste masses have been presented in multiple studies by Yesiller et al. (2005), Hanson et al. (2010b), and Yesiller et al. (2011). The elevated temperatures promote decomposition and degradation of wastes. The temperatures also were relatively high at the mid-depths of the waste mass in this investigation (Table 5). The high temperatures were in line with the high $D O D$, low organic content, and high $G_{s}$ at central locations in the landfill.

The overall decomposition and degradation of the wastes and the reduced particle sizes altogether resulted in the high $G_{s}$ values for the old wastes. The inert stable constituents of MSW such as metal, glass, and soil in general have higher $G_{s}$ values than the degradable organic constituents such as food, paper, and wood (Table 2), which resulted in increased $G_{s}$ values upon degradation and decomposition of the waste mass in time. In addition, the particle sizes of the old wastes were significantly smaller than the particle sizes of the manufactured and fresh wastes. The old wastes had a soil-like appearance and a more uniform composition than the fresh and manufactured wastes (Fig. 4). Individual constituent components were not easily distinguishable in the old wastes in contrast to the easily discernible components in the fresh and manufactured wastes. The size reduction of the particles likely resulted from combined effects of decomposition of the waste mass and crushing/breaking of the waste constituents under the load applied by the overlying wastes. Potential access to previously occluded voids and deformation of particles due both to biochemical degradation processes and applied mechanical stresses from overlying layers likely contributed to the high specific gravity values for the old wastes.

\subsection{Practical implications}

Unlike soils, the $G_{s}$ for MSW was not unique, but varied in a landfill environment. Characteristics of the constituent materials and the processes that occur within landfills resulted in the variable $G_{s}$. Variations were observed between uncompacted and compacted conditions and between fresh and old wastes. The increase due to compaction at placement (on the order of 0.186 , from 1.072 to 1.258 ) was less than the increase over time (on the order of 0.943 , from 1.258 to 2.201 ).

The $G_{s}$ varied due both to physical/mechanical processes and biochemical processes. The physical/mechanical processes were prevalent for fresh wastes including reduction of particle sizes and crushing and compression of particles due to mechanical loads such as compaction loading resulting in exposure of previously occluded intraparticle voids and compression of these voids. Combined biochemical and physical/mechanical processes were applicable to variation of $G_{s}$ for old wastes including loss of biodegradable matter in time due to decomposition of wastes and particle crushing and compression due to applied mechanical stresses from overlying waste layers. These observations were supported by the waste particle classifications as summarized by Hudson et al. (2004): Class A - inert stable materials; Class B - highly deformable materials including crushable/breakable particles and compressible materials that undergo significant physical changes; and Class C - readily biodegradable materials that undergo volumetric and phase composition changes. For fresh wastes, variations in $G_{s}$ occurred due mainly to effects on Class B particles, whereas for old wastes, variations in $G_{s}$ resulted from effects on Class B and Class $C$ particles.

Accurate knowledge of $G_{s}$ provides ability to determine quantities of solid, liquid, and gas phases per unit volume, which are required for accurate assessment of leachate, gas, and heat production and transfer for wastes (e.g., Zornberg et al., 1999; Hanson et al., 2000; Jain et al., 2005; Reddy et al., 2009b; Stoltz et al., 2010b; Breitmeyer, 2011). Variability in specific gravity needs to be considered in analysis of micro and macrostructure and constitutive relationships of MSW through determination of phase relations and characteristic physical parameters. For example, settlement calculations and models that utilize void ratio (e.g., Sowers, 1973; Bjarngard and Edgers, 1990; Landva and Clark, 1990; Hudson et al., 2004; Durmusoglu et al., 2006; Oweis, 2006; Babu et al., 2010; Bareither et al., 2012) require detailed weightvolume relationships. Accurate knowledge of $G_{s}$ is needed to evaluate and determine the void ratio associated with given waste densities and moisture contents representing a particular waste state (age and geostatic stress conditions). This in turn provides ability to convert between strain-based and void-ratio-based settlement calculations.

Table 5

Summary of waste parameters with depth.

\begin{tabular}{|c|c|c|c|c|c|}
\hline Average depth $(\mathrm{m})$ & $\mathrm{G}_{\mathrm{s}}$ & Organic content & $D O D(\%)$ & Average temperature $\left({ }^{\circ} \mathrm{C}\right)$ & Average age (Months) \\
\hline 0 (Surface) & 1.162 & 0.772 & 0 & 18.2 & 0 \\
\hline 3.4 & 2.237 & 0.157 & 95 & 33.6 & 31 \\
\hline 5.6 & 2.235 & 0.180 & 94 & 37.4 & 70 \\
\hline 12.4 & 2.161 & 0.361 & 83 & 34.2 & 85 \\
\hline
\end{tabular}


The specific gravities determined in this study can be used to establish phase parameters for the wastes at different states. If the fresh waste has a volume of solids of $1 \mathrm{~cm}^{3}$ at uncompacted conditions $\left(G_{s}=1.072\right)$, the same solid material would have a volume of $0.85 \mathrm{~cm}^{3}$ when the waste is compacted $\left(G_{s}=1.258\right)$, and would have a volume of $0.49 \mathrm{~cm}^{3}$ when the waste ages in place $\left(G_{s}=2.201\right)$. The difference in volume of $0.15 \mathrm{~cm}^{3}$ from uncompacted to compacted conditions represents a limit to the variation in intraparticle void volumes. The difference in volume of $0.51 \mathrm{~cm}^{3}$ from fresh to old wastes represents a limit for the variation in void volume due to reduction in intraparticle voids and loss of solid matter due to degradation. These volumetric estimates can be adopted for analyses (e.g., geomechanical response of wastes and flow of fluids through wastes) incorporating void ratio or other phase parameters on wastes under similar conditions to those included in this investigation.

Specific gravity testing is recommended to be conducted not only using representative waste composition, but also using representative stress state and history and degradation conditions. Tests can be repeated in time to provide representative values for longterm studies and analyses. When data are not available, $G_{s}$ values of 1.1 and 1.3 may be used for as-delivered/uncompacted and compacted fresh wastes, respectively for conditions similar to the landfill site presented herein. A higher $G_{s}$ of 2.2 may be used for older wastes at depth subjected to decomposition and mechanical stress in the landfill environment.

\section{Summary and conclusions}

This study was conducted to evaluate experimental determination of specific gravity of municipal solid waste. Factors that influence the specific gravity of wastes were investigated using tests conducted on manufactured wastes and both fresh and old wastes obtained from a landfill in the US. The fresh waste samples were collected immediately before and after compaction at the landfill. The old waste samples were obtained from depths ranging from 1.5 to $14.6 \mathrm{~m}$ with corresponding waste ages between 0.7 and 6 years. In particular, the effects of waste constituent particle size, compaction, and overall landfill environment were investigated. Manufactured wastes were used to assess $G_{s}$ without the influence of compositional variability between test specimens. The fresh and old waste specimens were used to assess the effects of waste compaction during placement in the short term and degradation and stress history with time in the long term.

Water pycnometry, typically used for soils, was adapted for testing MSW. A large 2000-mL-capacity flask and specimens with 100-350 g mass were used. Water pycnometry was effective for testing MSW as experimentally determined and calculated $G_{s}$ values (1.377 and 1.366) were similar for as-prepared/uncompacted manufactured wastes.

Waste specific gravity increased with decreasing particle size, due to compaction, and due to degradation and applied mechanical stresses over time in the landfill environment. For manufactured wastes, the average specific gravities were $1.377,1.523$, and 1.538 for as-prepared/uncompacted, compacted at the dry of optimum moisture content, and compacted at the wet of optimum moisture content specimens, respectively. The $G_{s}$ increased by 0.055-0.103 as the specimen particle sizes decreased from coarse to fine. The increases were higher for the uncompacted $(0.080$ and 0.103 ) than the compacted specimens (0.055 and 0.070). Also, waste specific gravity increased due to compaction. For manufactured wastes, the $G_{s}$ increased by 0.146 and 0.161 for dry of optimum and wet of optimum moisture content specimens, respectively compared to the uncompacted specimens. For fresh wastes, the $G_{s}$ increased by 0.186 from 1.072 for as-delivered uncompacted specimens to 1.258 for compacted specimens. In addition, the $G_{s}$ increased in the landfill environment over time. The $G_{s}$ for the old wastes varied between 2.162 and 2.276 (average 2.201), which was significantly higher than the $G_{s}$ for fresh wastes and the $G_{s}$ for manufactured wastes. The average organic content and degree of decomposition were $77.2 \%$ and $0 \%$, respectively for fresh wastes and $22.8 \%$ and $88.3 \%$, respectively for old wastes.

The increases in $G_{s}$ with decreasing particle size were attributed to potential exposure of previously occluded intraparticle voids and access to these voids due to the reduction in the size of the individual waste constituent particles. Similarly, compaction resulted in decreases in the waste particle sizes and access to occluded intraparticle voids as well as deformation of particles. Loss of low $G_{s}$ biodegradable components due to decomposition, potential access to previously occluded voids, and deformation of particles due both to degradation processes and applied mechanical stresses contributed to the high specific gravities for the old wastes. The $G_{s}$ was correlated to the degree of decomposition with a linear relationship. Unlike soils, the $G_{s}$ for MSW was not unique, but varied in a landfill environment due both to physical/mechanical processes and biochemical processes. Characteristics of the constituent materials and the processes that occur within landfills resulted in the variable $G_{s}$. Variability in specific gravity needs to be considered in analysis of micro and macrostructure and constitutive relationships of MSW determined using phase relations and characteristic physical parameters.

\section{Acknowledgements}

Funding for the investigation was provided by the City of Santa Maria, California and the Global Waste Research Institute at California Polytechnic State University. The assistance of Mr. Jeffrey Clarin (Solid Waste Manager, City of Santa Maria), Mr. Douglas Shearer (Heavy Equipment Lead Operator, City of Santa Maria), and the staff at Santa Maria Regional Landfill are greatly appreciated. Ms. Noce was supported by funds provided by the National Science Foundation under REU Site Grant: EEC-1263337.

\section{References}

Andersland, O.B., Khattak, A.S., Al-Khafaji, A.W.N., 1981. Effect of organic material on soil shear strength. In: Yong, R.N., Townsend, F.C. (Eds.), Laboratory Shear Strength of Soil, ASTM STP 740. ASTM, West Conshohocken, PA, pp. 226-242.

ASTM D 854, 2010. Standard Test Methods for Specific Gravity of Soil Solids by Water Pycnometer. Annual Book of ASTM Standards. American Society for Testing and Materials, West Conshohocken, PA.

ASTM D1557 2012. Standard Test Methods for Laboratory Compaction Characteristics of Soil Using Modified Effort (56,000 ft-lbf/ $\mathrm{ft}^{3}(2,700 \mathrm{kN}-\mathrm{m} /$ $\left.\mathrm{m}^{3}\right)$ ). Annual Book of ASTM Standards. American Society for Testing and Materials, West Conshohocken, PA.

ASTM D2974, 2012. Standard Test Methods for Moisture, Ash, and Organic Matter of Peat and Other Organic Soils. Annual Book of ASTM Standards. American Society for Testing and Materials, West Conshohocken, PA.

Babu, G.L.S., Reddy, K.R., Chouksey, S.K., 2010. Constitutive model for municipal solid waste incorporating mechanical and biodegradation-induced compression. Waste Manage. 30, 11-22.

Bareither, C.A., Benson, C.H., Edil, T.B., 2012. Compression behavior of municipal solid waste: immediate compression. J. Geotech. Geoenviron. Eng. 138 (9), 1047-1062.

Beaven, R.P., 2000. The Hydrogeological and Geotechnical Properties of Household Waste in Relation to Sustainable Landfilling. Ph.D. Dissertation, Queen Mary and Westfield College, University of London.

Bjarngard, A., Edgers, L., 1990. Settlement of municipal solid waste landfills. In: Proceedings of the 13th Annual Madison Waste Conference, Madison, WI, pp. 192-205.

Breitmeyer, R.J., 2011. Hydraulic Characterization of Municipal Solid Waste. Ph.D. Dissertation, University of Wisconsin-Madison, Madison, WI.

Durmusoglu, E., Sanchez, I.M., Corapcioglu, M.Y., 2006. Permeability and compression characteristics of municipal solid waste samples. Environ. Geol. 50, 773-786.

Entenmann, W., Wendt, P., 2007. Placement and compaction of treated municipal solid waste in modern landfills, results of geotechnical and hydraulic tests and monitoring. In: Proceedings of the Sardinia 2007, Eleventh International Waste Management and Landfill Symposium, CD-ROM. 
Gourc, J.-P., Staub, M.J., Conte, M., 2010. Decoupling MSW settlement into mechanical and biochemical processes - modelling and validation on largescale setups. Waste Manage. 30, 1556-1568.

Hanson, J.L., Edil, T.B., Yesiller, N., 2000. Thermal properties of high water content materials. In: Edil, T.B., Fox, T.J. (Eds.), Geotechnics of High Water Content Materials, ASTM STP 1374. ASTM, West Conshohocken, PA, pp. 137-151.

Hanson, J.L., Yesiller, N., Von Stockhausen, S.A., Wong, W.W., 2010a. Compaction characteristics of municipal solid waste. J. Geotech. Geoenviron. Eng. 136 (8), 1095-1102.

Hanson, J.L., Yesiller, N., Oettle, N., 2010b. Spatial and temporal temperature distributions in municipal solid waste landfills. J. Environ. Eng. 136 (8), $804-$ 814

Hettiarachchi, C.H., 2005. Mechanics of Biocell Landfill Settlements. Ph.D. Dissertation, New Jersey Institute of Technology, Newark, NJ.

Hudson, A.P., White, A.K., Beaven, R.P., Powrie, W., 2004. Modeling the compression behaviour of landfilled domestic waste. Waste Manage. 24, 259-269.

Jain, P., Powell, J., Townsend, T.G., Reinhart, D.R., 2005. Air permeability of waste in a municipal solid waste landfill. J. Environ. Eng. 131 (11), 1565-1573.

Landva, A.O., Clark, J.I., 1990. Geotechnics of waste fill. In: Geotechnics of Waste Fill - Theory and Practice, ASTM STP 1070. ASTM, Philadelphia, PA, pp. 86-106.

McDougall, J., 2007. A hydro-bio-mechanical model for settlement and other behaviour in landfilled waste. Comput. Geotech. 34, 229-246.

Millspaugh, A.M., Tinjum, J.M., Boecher, T.A., 2010. Specific gravity of expansive chromium ore processing residue with complex microstructure. Geotech. Test. J. 33 (4), 322-328.

Olivier, F., Gourc, J.-P., 2007. Hydro-mechanical behavior of municipal solid waste subject to leachate recirculation in a large-scale compression reactor cell. Waste Manage. 27, 44-58.

Oweis, I.S., 2006. Estimate of landfill settlement due to mechanical and decompositional processes. J. Geotech. Geoenviron. Eng. 132 (5), 644-650.

Powrie, W., Beaven, R.P., 1999. Hydraulic properties of household waste and implications for liquid flow in landfills. In: Proceedings of the Institution of Civil Engineers, Geotechnical Engineering, October 1999.

Qian, X., Koerner, R.M., Gray, D.H., 2005. Geotechnical Aspects of Landfill Design and Construction. Prentice-Hall Inc., Upper Saddle River, New Jersey.

Reddy, K.R., Gangathulasi, J., Parakalla, N., Hettiarachchi, H., Bogner, J.E., Lagier, T., 2009a. Compressibility and shear strength of municipal solid waste under short-term leachate recirculation operations. Waste Manage. Res. 27 (6), 578587.
Reddy, K.R., Hettiarachchi, H., Parakalla, N., Gangathulasi, J., Bogner, J., Lagier, T. 2009b. Hydraulic conductivity of MSW in landfills. J. Environ. Eng. 135 (8), 677 683.

Reddy, K.R., Hettiarachchi, H., Gangathulasi, J., Bogner, J., 2011. Geotechnical properties of municipal solid waste at different phases of biodegradation. Waste Manage. 31, 2275-2286.

Sowers, G.F., 1973. Settlement of waste disposal fills. In: Proceedings of the 8th International Conference on Soil Mechanics and Foundation Engineering, Moscow, vol. 1, pp. 207-210.

Stoltz, G., Gourc, J.-P., Oxarango, L., 2010a. Characterisation of the physicomechanical parameters of MSW. Waste Manage. 30, 1439-1449.

Stoltz, G., Gourc, J.-P., Oxarango, L., 2010b. Liquid and gas permeabilities of unsaturated municipal solid waste under compression. J. Contam. Hydrol. 118, 27-42.

Tamari, S., Samaniego-Martinez, D., Bonola, I., Bandala, E.R., Ordaz-Chaparro, V. 2005. Particle density of volcanic scoria determined by water pycnometry. Geotech. Test. J. 28 (4), 321-327.

Tinjum, J.M., Benson, C.H., Edil, T.B., 2008. Mobilization of Cr(VI) from chromite ore processing residue through acid treatment. Sci. Total Environ. 391, 13-25.

USEPA, 2010. Municipal Solid Waste in the United States: 2009 Facts and Figures. EPA530-R-10-012, Washington, DC.

Wesley, L.D., 2001. Determination of specific gravity and void ratio of pumice materials. Geotech. Test. J. 24 (4), 418-422.

Wong, W.W., 2009. Investigation of Geotechnical Properties of Municipal Solid Waste. M.S. Thesis, California Polytechnic State University, San Luis Obispo, California.

Wu, H., Wang, H., Zhao, Y., Chen, T., Lu, W., 2012. Evolution of unsaturated hydraulic properties of municipal solid waste with landfill depth and age. Waste Manage. $32,463-470$.

Yesiller, N., Hanson, J.L., Liu, W.-L., 2005. Heat generation in municipal solid waste landfills. J. Geotech. Geoenviron. Eng. 131 (11), 1330-1344.

Yesiller, N., Hanson, J.L., Yoshida, H., 2011. Landfill temperatures under variable decomposition conditions. In: Han, J., Alzamora, D.E. (Eds.), Advances in Geotechnical Engineering, ASCE GSP 211. ASCE, pp. 1055-1065.

Zornberg, J.G., Jernigan, B.L., Sanglerat, T.R., Cooley, B.H., 1999. Retention of free liquids in landfills undergoing vertical expansion. J. Geotech. Geoenviron. Eng. 125 (7), 583-594. 